\title{
Exigências de lisina digestível para juvenis de tilápia-do-nilo
}

\section{Wilson Massamitu Furuya ${ }^{1}$, Vivian Gomes dos Santos ${ }^{3}$, Lilian Carolina Rosa Silva ${ }^{2}$, Valéria Rossetto Barriviera Furuya ${ }^{1}$, Eduardo Shiguero Sakaguti ${ }^{1}$}

\footnotetext{
1 Depto. de Zootecnia - UEM, Av. Colombo, 5790, 87020-900, Maringá-PR.

2 Programa de Pós-graduação em Zootecnia - PPZ/UEM, Maringá-PR.

3 Graduação em Zootecnia, UEM, Maringá-PR.
}

RESUMO - Este estudo foi realizado com o objetivo de determinar a exigência de lisina digestível para juvenis de tilápia-do-nilo. Noventa e seis peixes revertidos sexualmente e com peso vivo inicial de 5,72 $\pm 0,10 \mathrm{~g}$ foram alimentados por 42 dias com quatro rações $(29.51 \%$ de PB e $3.235 \mathrm{kcal}$ de energia digestível $/ \mathrm{kg})$ contendo diferentes níveis de L-lisina $\mathrm{HCl}(0,1 ; 0,3 ; 0,5$ e $0,7 \%$, correspondendo a rações com 1,$04 ; 1,27 ; 1,51$ e $1,741 \%$ de lisina digestível, respectivamente). Os peixes foram distribuídos em 16 tanques com capacidade de $1.000 \mathrm{~L}$ cada um, em um delineamento inteiramente casualizado, com quatro tratamentos, três repetições e seis peixes por unidade experimental. Não foi observado efeito dos níveis de lisina sobre o índice hepato-somático, a gordura visceral, a sobrevivência e os teores de água e extrato etéreo na carcaça. A análise de Linear Response Plateau do ganho de peso e da conversão alimentar versus níveis de lisina digestível demonstrou estimativa de exigência de 1,56 e 1,44\% de lisina digestível, respectivamente. Foi observado efeito quadrático sobre o rendimento de carcaça, que aumentou até o nível de 1,61\% de lisina digestível. Considerando o desempenho, recomenda-se que dietas para juvenis de tilápia-do-nilo devem conter 1,44\% de lisina digestível (5,23\% da proteína da dieta).

Palavras-chave: desempenho, exigência, lisina, Oreochromis niloticus

\section{Digestible lysine requirements of Nile tilapia juveniles}

\begin{abstract}
This trial was carried out to determine the digestible lysine requirements of Nile tilapia juveniles. Ninetysix reverted fishes averaging initial weight of $5.72 \pm 0.10 \mathrm{~g}$ were fed four diets $(29.51 \%$ of crude protein and $3,235 \mathrm{kcal} / \mathrm{kg}$ of digestible energy) containing increasing levels of L-lysine $\mathrm{HCl}(0.1,0.3,0.5$, and $0.7 \%)$, during 42 days. The following treatments were evaluated: dietary lysine levels of $1.04 ; 1.27 ; 1.51$ and $1.741 \%$. Fishes were allotted to $1000-\mathrm{L} 16$ tanks, as a completely randomized design with four treatments, three replicates and eight fishes per experimental unit. No treatment effects on hepatosomatic index, visceral fat, survival rate and water ether extract in the carcass were observed. The Linear Response Plateau analysis of weight gain and feed:gain ratio versus digestible lysine level yielded an estimated digestible lysine requirement of 1.56 and $1.44 \%$ for Nile tilapia juveniles, respectively. Quadratic effect of treatments on carcass yield that increased up to $1.61 \%$ of digestible lysine was observed. Considering the performance, it is recommended diets containing up to $1.44 \%$ of digestible lysine $(5.23 \%$ of protein) for Nile tilapia juveniles.
\end{abstract}

Key Words: lysine, Oreochromis niloticus, performance, requirement

\section{Introdução}

A tilápia-do-nilo (Oreochromis niloticus) é uma espécie de água doce cuja criação vem aumentando rapidamente no Brasil, principalmente em sistemas intensivos (Fitzsimmons, 2000). Em altas densidades, os peixes necessitam de dietas completas, uma vez que o alimento natural disponível no meio aquático não atende às suas exigências nutricionais.

Diversos alimentos protéicos de origem vegetal têm sido utilizados em substituição à farinha de peixe, pela maior disponibilidade no mercado e, conseqüentemente, pelo menor custo. Entretanto, por apresentarem deficiência de alguns aminoácidos, é necessária a suplementação com aminoácidos sintéticos.

Para adequada suplementação, é necessário o conhecimento da exigência de cada aminoácidos essencial, principalmente os mais limitantes. A lisina geralmente é o primeiro ou segundo aminoácido limitante em dietas para peixes, sendo encontrada em elevada proporção na carcaça (Furuya et al., 2004). A suplementação de lisina está relacionada ao aumento no ganho de peso, à melhora na conversão alimentar, ao aumento na retenção de nitrogênio e à redução 
no conteúdo de lipídios na carcaça (Bai \& Gatlin, 1994; Davis et al., 1997; Berge et al., 1998).

A exigência de lisina tem sido avaliada para juvenis de diversas espécies carnívoras, como o sea bass, Dicentrarchus labrax (Tibaldi \& Lanari, 1991), o striped bass, Morone chysops $x$ M. saxatilis (Keembiyehetty \& Gatlin,1992) e a truta arco-íris, Oncorhynchus mykiss (Kim et al., 1992). Para juvenis de espécies herbívoras e onívoras, o teor de lisina na dieta é de aproximadamente 1,5 ou $5 \%$ da proteína da dieta, como pode ser observado nos trabalhos realizados por Santiago \& Lovell (1988), com tilápias-do-nilo, Murthy \& Varghese (1997), com carpa (Labeo rohita), Forster \& Ogata (1998), com juvenis de flounder (Paralichthys olivaceus) (1 g), Fagbenro et al. (1998), com o bagre africano (Clarias gariepinus), e Ahmed \& Khan (2004), com a carpa (Cirrhinus mrigala).

A deficiência de um único aminoácido na dieta pode limitar a utilização de toda a proteína pelos peixes. Além disso, a digestibilidade dos aminoácidos é bastante variável entre os ingredientes (Furuya et al., 2001a). Considerando que ainda são poucas as informações sobre as exigências de aminoácidos digestíveis para a tilápia-do-nilo, é importante apresentar as exigências em forma de aminoácido digestível para permitir a adequada utilização da proteína da ração pelos peixes e reduzir o custo com alimentação.

Este trabalho foi realizado com o objetivo de determinar a exigência de lisina digestível para juvenis de tilápiado-nilo, considerando o crescimento, a utilização dos nutrientes e a composição química da carcaça.

\section{Material e Métodos}

O experimento foi realizado no Laboratório de Aqüicultura da Universidade Estadual de Maringá - UEM, Maringá-PR, durante 42 dias.

Foram utilizados 96 peixes da linhagem tailandesa revertidos durante a fase larval, com peso inicial de 5,72 \pm $0,10 \mathrm{~g}$, originados da Piscicultura Araucária Belmonte, Rolândia-PR. Os peixes foram distribuídos em 16 aquários com volume útil unitário de $800 \mathrm{~L}$, com sistema individual de renovação da água ( $5 \% /$ dia) e aeração constante por meio de pedra porosa acoplada a um soprador central.

Foram avaliadas rações com 0; 3,00; 6,00 e 9,00 g de L-lisina $\mathrm{HCl}(78,9 \%) / \mathrm{kg}$, correspondentes a rações com 1,$04 ; 1,27 ; 1,51$ e $1,74 \%$ de lisina digestível ou 1,$17 ; 1,48 ; 1,63$ e $1,79 \%$ de lisina total, respectivamente.

Uma ração-referência foi formulada para atender às exigências de PB estimadas para tilápia-do-nilo por Furuya et al. (2000), mantendo-se a relação proteína:energia próxima à recomendada pelo NRC (1993) para tilápias (Tabela 1).
Tabela 1 - Composições percentual e calculada da raçãoreferência

Table 1 - Ingredient and calculated compositions of the reference diet

Ingrediente (\%)

Ingredient

Milho (Corn)

39,43

Farelo de soja (Soybean meal)

24,00

Glúten de milho (Corn gluten)

20,00

Farelo de trigo (Wheat meal)

8,00

Farinha de peixe (Fish meal)

4,00

Fosfato bicálcico (Dicalcium phosphate)

Óleo de soja (Soy oil)

1,00

DL-metionina (DL-methionine)

0,20

Suplemento mineral e vitamínico ${ }^{1}$ (Min. and vit. mix) 0,50

Sal comum (Salt)

0,50

Vitamina $\mathrm{C}^{2}($ Vitamin $C)$

0,05

$\mathrm{BHT}^{3}$

0,02

Alginato ${ }^{4}$ (Sodium alginate)

0,10

Total

100,00

Composição (matéria natural)

Composition (as-fed basis)

Matéria seca (\%) (Dry matter)

88,86

Energia digestível ( $\mathrm{kcal} / \mathrm{kg})$ (Digestible energy)

Proteína bruta (\%) (Crude protein)

$3.235,33$

Proteína digestível (\%) (Digestible protein)

29,83

Extrato etéreo (\%) (Ether extract)

27,51

Fibra bruta (\%) (Crude fiber)

2,82

Cálcio (\%) (Calcium)

Fósforo disponível (\%) (Available phosphorus)

3,06

0,82

0,57

Aminoácido digestível $(\%)^{6}$ (Digestible amino acids)

Lisina (Lysine)

Metionina (Methionine)

1,04

Metionina + cistina (Methionine + cystine)

0,75

Treonina (Threonine)

1,15

Triptofano (Tryptophan)

0,98

0,24

Arginina (Arginine)

1,11

1 Suplemento mineral e vitamínico (mineral and vitamin mix) (Supre Mais): composição por $\mathrm{kg}$ do produto (composition per $\mathrm{kg}$ the product): Vit. $A=1200.000$ Ul; vit. $D 3=200.000$ Ul; vit. $E=12.000 \mathrm{mg}$; vit. $K 3=2.400 \mathrm{mg}$; vit. $B 1=4.800 \mathrm{mg}$; vit. $B 2=4.800 \mathrm{mg}$; vit. $B 6=4.000 \mathrm{mg}$ vit. B12 $=4.800 \mathrm{mg}$; ác. fólico (folic acid) $=1.200 \mathrm{mg}$; pantotenato de $\mathrm{Ca}$ (pantothenic calcium) $=12.000 \mathrm{mg}$ : vit. $\mathrm{C}=48.000 \mathrm{mg}$; biotina (biotin) $=48 \mathrm{mg}$ colina (choline) $=65.000 \mathrm{mg}$; ácido nicotínico $($ nicotinic acid $)=24.000 \mathrm{mg}$ $\mathrm{Fe}=10.000 \mathrm{mg} ; \mathrm{Cu}=600 \mathrm{mg} ; \mathrm{Mn}=4.000 \mathrm{mg} ; \mathrm{Zn}=6.000 \mathrm{mg} ; \mathrm{I}=20 \mathrm{mg}$ $\mathrm{Co}=2 \mathrm{mg}$ e $\mathrm{Se}=20 \mathrm{mg}$;

2 Vitamina C: sal cálcico 2 - monofosfato de ácido ascórbico com $42 \%$ de princípio ativo) (Vitamin C: calcic salt, 2-monophosphate of ascorbic acid-42\% active principle).

3 Butil Hidróxi Tolueno (Butil-hidroxi-toluen).

${ }^{4}$ Aglutinante (Aglutinant)

${ }^{5}$ Valores determinados no Laboratório de Nutrição Animal -DZO/UEM. (Analyses were performed at the Nutrition Lab of DZO/UEM).

6 Valores determinados no Laboratório de Alta Tecnologia, Campinas-SP. (Analyses were performed at LABTEC, Campinas-SP).

Os aminoácidos DL-metionina e L-treonina foram suplementados na ração-referência, com base no conceito de proteína ideal (Furuya et al., 2001a), para tilápia-do-nilo.

Antes da montagem do experimento, foi determinada a digestibilidade aparente da energia bruta, dos nutrientes e dos aminoácidos da ração-referência, utilizando-se metodologia descrita por Furuya et al. (2001b). Os coeficientes de digestibilidade foram determinados de acordo com a expressão descrita por Nose (1960): 


$$
C D A=100-\left[100 \cdot\left(\frac{\% C r_{2} O 3_{r}}{\% C r_{2} O 3_{f}}\right) \cdot\left(\frac{\% N_{f}}{\% N_{r}}\right)\right]
$$

em que: $\mathrm{CDA}=$ coeficiente de digestibilidade aparente (\%); $\% \mathrm{Cr}_{2} \mathrm{O} 3_{\mathrm{d}} \mathrm{e} \% \mathrm{Cr}_{2} \mathrm{O} 3_{\mathrm{f}}=\%$ de óxido de crômo na ração e nas fezes, respectivamente; $\% \mathrm{~N}_{\mathrm{f}} \mathrm{e} \% \mathrm{~N}_{\mathrm{d}}=\%$ de nutriente nas fezes e na ração, respectivamente.

Todos os ingredientes foram moídos até atingirem diâmetro igual ou inferior a $0,36 \mathrm{~mm}$. As rações foram granuladas por meio de uma prensa elétrica e, após desidratação em estufa ventilada a $50^{\circ} \mathrm{C}$, durante 24 horas, foram desintegradas até o diâmetro recomendado por Jauncey \& Ross (1982) para tilápias.

As análises químicas dos alimentos, das rações e das carcaças foram feitas no Laboratório de Análise de Alimentos do Departamento de Zootecnia da Universidade Estadual de Maringá - UEM, de acordo com metodologia descrita por Silva et al. (1990). A análise dos aminoácidos da raçãoreferência e das fezes foi realizada no Laboratório de Alta Tecnologia - LABTEC, Campinas-SP, e a de óxido de cromo foi feita conforme descrito por Graner et al. (1972).

Todos os peixes foram pesados no início e ao final do experimento. A ração diária total foi distribuída quatro vezes/dia, às $8,11 \mathrm{~h} 30,15 \mathrm{e} 18 \mathrm{~h}$. O arraçoamento foi manual e a dieta foi fornecida até a saciedade aparente, quando não se observaram captura e regurgitação dos grânulos.

Após pesagem final, dois peixes de cada unidade experimental foram utilizados para determinação do rendimento de carcaça (peso da carcaça isenta de vísceras/peso vivo x 100), do teor de gordura visceral (peso da gordura viscero-somática/ peso vivo x 100) e do índice hepato-somático (peso do fígado/ peso vivo x 100). A taxa de eficiência protéica e a eficiência de retenção de nitrogênio foram calculadas de acordo com as expressões descritas por Jauncey \& Ross (1982).

Diariamente, foram tomadas as medidas de temperatura (8 e 16h) da água dos tanques e, a cada cinco dias, foram realizadas as medidas de $\mathrm{pH}$, oxigênio dissolvido $(\mathrm{mg} / \mathrm{L}) \mathrm{e}$ condutividade elétrica $(\mu \mathrm{Sm} / \mathrm{cm})$ da água de cada tanque. Os dados foram obtidos por meio de kit digital portátil.

Os peixes foram distribuídos em delineamento inteiramente casualisado, com quatro tratamentos e quatro repetições, considerando-se unidade experimental cada tanque de $0,8 \mathrm{~m}^{3}$ de água, com seis peixes.

Os dados foram submetidos às análises de variância (ANOVA) e regressão polinomial e/ou LRP (Linear Response Plateau), por meio do programa estatístico SAEG (Euclydes, 1983). Os dados de sobrevivência foram transformados pela expressão $y=\operatorname{arcsen} \sqrt{x / 100}$, em que $x$ é o valor da variável, em porcentagem.
O modelo estatístico utilizado para análise das características de desempenho e econômicas foi:

$$
Y_{i j}=b_{0}+b_{1}\left(h_{i}-h\right)+b_{2}\left(h_{i}-h\right)^{2}+e_{i j}
$$

em que: $Y_{i j}=$ observação referente ao tanque $j$, em que se utilizou nível de lisina digestível $\mathrm{i} ; \mathrm{b}_{0}=$ constante; $\mathrm{b}_{1}=$ coeficiente linear de regressão da variável Y conforme o nível de lisina digestível i, para todo i diferente de 1; $\mathrm{b}_{2}=$ coeficiente quadrático de regressão da variável $\mathrm{Y}$, conforme o nível de lisina digestível i, para todo i diferente de $1 ; h_{i}=$ da porcentagem do nível de lisina digestível $\mathrm{i}$, sendo $\mathrm{i}=1,2,3$ e 4 e $\mathrm{i}_{1}=1,04 ; \mathrm{i}_{2}=1,27 ; \mathrm{i}_{3}=1,51 \mathrm{e}_{4}=1,74 \%$; $\mathrm{h}=$ média da porcentagem do nível de lisina digestível e $\mathrm{e}_{\mathrm{ij}}=$ erro aleatório associado a cada observação.

\section{Resultados e Discussão}

Foram obtidos valores de $26,3 \pm 1,55^{\circ} \mathrm{C} ; 6,24 \pm 0,5 \mathrm{mg} / \mathrm{L}$; $7,46 \pm 0,12$ e $240,05 \pm 14,8 \mu \mathrm{Sm} / \mathrm{cm}$, respectivamente, para temperatura, oxigênio dissolvido, $\mathrm{pH}$ e condutividade elétrica da água dos tanques. Os parâmetros obtidos encontram-se na faixa recomendada por Popma \& Green (1990) para máximo crescimento das tilápias.

Geralmente, os trabalhos realizados para determinação de aminoácidos para peixes foram obtidos com alevinos, por meio de dietas semipurificadas ou purificadas, de modo que os coeficientes de digestibilidade da energia e proteína foram estimados, e não determinados como realizado neste trabalho. Além disso, os dados são apresentados em forma de aminoácidos totais, o que dificulta a comparação dos dados.

Os valores médios de desempenho de juvenis de tilápiado-nilo alimentados com dietas contendo valores crescentes de lisina digestível encontram-se na Tabela 2.

Não foi observado efeito $(\mathrm{P}<0,05)$ dos níveis de lisina digestível nas dietas sobre a taxa de sobrevivência, a porcentagem de gordura visceral, o índice hepato-somático, a porcentagem de água e a porcentagem de gordura na carcaça.

Os resultados de índice hepato-somático e gordura visceral corroboram os descritos por Bai \& Gatlin (1994), em estudo realizado para determinação da exigência de lisina total para juvenis de bagre do canal. A ausência de diferenças entre os dados provavelmente está relacionada ao elevado desvio entre os dados, principalmente para o índice hepato-somático e a gordura visceral.

Com o incremento nos níveis de lisina nas dietas, foi observado aumento linear $(\mathrm{P}<0,01)$ sobre o ganho de peso. No entanto, pelo modelo descontínuo LRP (Linear Response Plateau), que melhor se ajustou aos dados $(\mathrm{P}<0,01)$, foi estimado em $1,56 \%$ o nível de lisina digestível $(1,72 \%$ de lisina total) em que ocorreu um platô (Figura 1), correspon- 
Tabela 2 - Desempenho de juvenis de tilápia-do-nilo alimentados com rações contendo níveis crescentes de lisina digestível Table 2 - Average performance values of Nile tilapia fed diets with increasing levels of digestible lysine

\begin{tabular}{|c|c|c|c|c|c|}
\hline \multirow[t]{2}{*}{$\begin{array}{l}\text { Variável } \\
\text { Variable }\end{array}$} & \multicolumn{4}{|c|}{$\begin{array}{c}\text { Lisina digestível (\%) } \\
\text { Digestible lysine }\end{array}$} & \multirow[b]{2}{*}{$\mathrm{CV}^{1}$} \\
\hline & 1,04 & 1,27 & 1,51 & 1,74 & \\
\hline Peso inicial (Initial weight) (g) & 5,58 & 5,87 & 5,75 & 5,69 & 4,34 \\
\hline Peso final (Final weight) (g) & 29,32 & 34,16 & 37,89 & 38,85 & 7,76 \\
\hline Ganho de peso (g) (Weight gain) ${ }^{2}$ & 23,74 & 28,29 & 32,14 & 33,16 & 9,65 \\
\hline Conversão alimentar (Feed:gain ratio) ${ }^{2}$ & 1,54 & 1,56 & 1,68 & 1,65 & 4,25 \\
\hline Taxa de eficiência protéica (Protein efficiency ratio) ${ }^{3}$ & 2,32 & 2,61 & 2,67 & 2,99 & 3,95 \\
\hline Retenção de nitrogênio (Nitrogen retention) (\%) & 22,58 & 24,79 & 37,74 & 35,68 & 2,86 \\
\hline Índice hepato-somático (Hepatosomatic index) (\%) & 1,87 & 2,12 & 2,33 & 1,92 & 8,83 \\
\hline Gordura visceral (Visceral fat) (\%) & 0,26 & 0,43 & 0,44 & 0,45 & 19,81 \\
\hline Sobrevivência (Survival) (\%) & 83,33 & 83,33 & 91,67 & 83,33 & 16,79 \\
\hline Rendimento de carcaça (\%) (Carcass yield $)^{4}$ & 82,49 & 83,67 & 85,97 & 85,95 & 1,77 \\
\hline
\end{tabular}

dente a 5,67\% de lisina digestível em relação ao conteúdo de proteína digestível da dieta.

Este valor (1,56\%) é superior ao encontrado por Santiago \& Lovell (1988), que estimaram exigência de 1,43\% de lisina ( $5,1 \%$ da proteína da dieta) para tilápia-do-nilo na fase inicial. Todavia, é inferior aos obtidos por Murthy \& Varghese (1997) e Fagbenro et al. (1998), de 2,24 (5,6\% da proteína)e $2,29 \%$ de lisina $(5,73 \%$ da proteína), em juvenis de carpa e bagre do canal, respectivamente, alimentados com rações formuladas com base no valor de lisina total. Quando o valor de lisina foi calculado como porcentagem da proteína da dieta, os valores estimados por esses últimos autores foram próximos aos registrados neste estudo.

A baixa proporção de lisina em relação ao conteúdo de proteína da dieta é observada principalmente em dietas com valores elevados de proteína, como pode ser observado no trabalho realizado com juvenis de red sea bream por Forster \& Ogata (1998), que estimaram valor de 1,73\% de lisina (3,3\% da proteína) na dieta para máximo ganho de peso dos peixes alimentados com rações com $48 \%$ de PB. Isso foi demonstrado anteriormente por Tibaldi \& Lanari (1991), que determinaram exigência de $2,17 \%$ de lisina $(4,34 \%$ da proteína) para alevinos de sea bass. Keembiyehetty \& Gatlin(1992), por sua vez, estimaram exigência de 1,41\% de lisina (4,03\% da proteína) para juvenis de striped bass. Trabalhando com truta arco-íris de aproximadamente 12,4 g de peso vivo, Kim et al. (1992) determinaram exigência de $1,30 \%$ de lisina na ração $(3,71 \%$ da proteína). Valores próximos foram obtidos por Berge et al. (1998), em juvenis de salmão do Atlântico, com valor de $1,8 \%$ de lisina na dieta para máximo ganho de peso $(3,6 \%$ de lisina em relação à $\mathrm{PB})$.

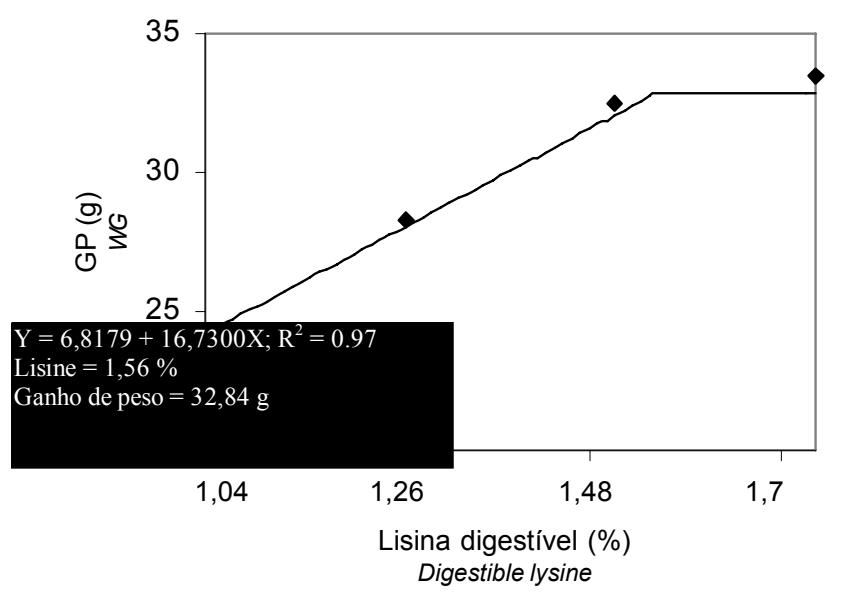

Figura 1 - Ganho de peso (GP) de juvenis de tilápia-do-nilo alimentados com rações contendo níveis crescentes de lisina digestível.

Figure 1 - Weight gain (WG) of juvenile Nile tilapia fed diets with increasing levels of digestible lysine.

Assim, a comparação dos dados com base em valores de porcentagem da lisina da dieta ou como porcentagem da lisina em relação à proteína da dieta é relativa, se consideradas as diferenças nos níveis de proteína. Além disso, é importante ressaltar que, neste estudo, a proporção de lisina foi obtida com base nos valores de lisina e proteína digestíveis, enquanto os demais autores obtiveram essa relação com base em valores brutos de lisina e proteína.

Pelo modelo descontínuo LRP (Linear Response Plateau), que melhor se ajustou aos dados $(\mathrm{P}<0,01)$, foi estimado em 1,44\% o nível de lisina digestível (1,72\% de lisina total), observando-se diferença para essa variável (Figura 2) correspondente a 5,23\% de lisina digestível em 
relação ao conteúdo de proteína digestível da dieta. Este resultado é inferior aos encontrados por Forster \& Ogata (1998) e Keembiyehetty \& Gatlin (1992), de 1,9 e 1,91\% lisina total em dietas para juvenis de flounder e striped bass, respectivamente, para melhor valor dessa variável.

$\mathrm{O}$ acréscimo de lisina nas dietas resultou em aumento crescente $(\mathrm{P}<0,05)$ nas variáveis de retenção de nitrogênio e taxa de eficiência protéica. Estes resultados divergem dos encontrados por Berge et al. (1998), para juvenis de salmão do Atlântico (1,6\% de lisina na dieta) e por Tibaldi \& Lanari (1991), que determinaram exigência de $2,17 \%$ de lisina para juvenis de sea bass $(0,85 \mathrm{~g})$ para máxima taxa de eficiência protéica. Diferem também dos resultados encontrados por Forster \& Ogata (1998), que estimaram exigência de 2,16 e $2,11 \%$ de lisina para alevinos de flounder japonês e para o red sea bream, respectivamente, para melhor taxa de eficiência protéica.

A elevação nos níveis de lisina digestível das dietas resultou em aumento linear $(\mathrm{P}<0,05)$ do rendimento de carcaça isenta de vísceras. A lisina é um aminoácido presente em elevada proporção no tecido muscular, de modo que a lisina da dieta é utilizada basicamente para a deposição de tecido

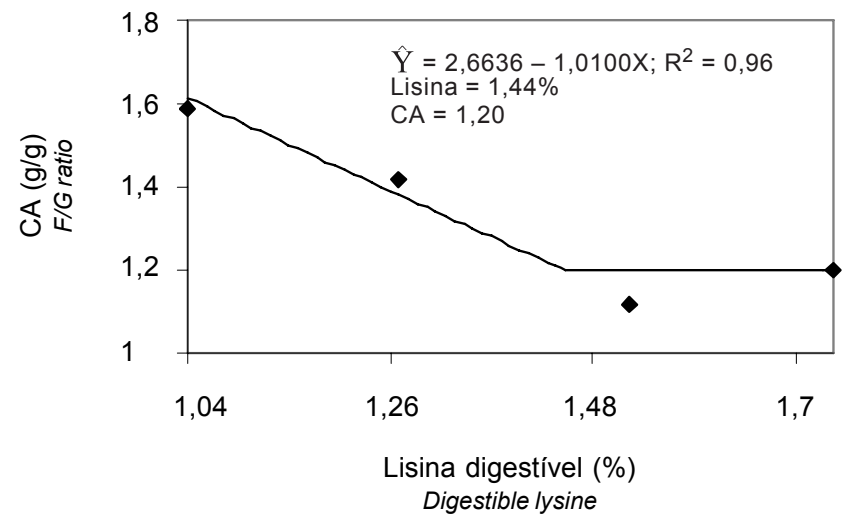

Figura 2 - Conversão alimentar (CA) de juvenis de tilápia-do-nilo alimentados com dietas contendo níveis crescentes de lisina digestível.

Figure 2 - Feed:gain ratio (F/G) of juvenile Nile tilapia fed diets with increasing levels of digestible lysine. muscular, pois não é um aminoácido gliconeogênico (Furuya et al., 2004). Os estudos realizados com o objetivo de determinar as exigências de lisina não têm determinado esta variável, ainda que seja importante, tendo em vista a elevada taxa de crescimento dos peixes durante a fase juvenil, diretamente relacionada à deposição de tecido muscular.

A utilização de níveis crescentes de lisina digestível nas dietas resultou em aumento linear $(\mathrm{P}<0,01)$ na composição em proteína bruta corporal (Tabela 3 ).

Em estudo para avaliar a suplementação de L-lisina $\mathrm{HCl}$ $(1,42 ; 2,14$ e $2,85 \%)$ em dietas para alevinos de bagre do canal, Zarate \& Lovell (1997) também observaram aumento linear no conteúdo de proteína corporal. Comparando o desempenho de juvenis de truta arco-íris alimentados com rações contendo 0,89 e 1,96\% de lisina, Rodehutscord et al. (2000) encontraram maior teor de proteína $(17,7 \%)$ na carcaça de peixes alimentados com dietas com maior conteúdo de lisina.

Por outro lado, os resultados de gordura visceral e porcentagem de gordura na carcaça obtidos neste estudo contrariam os obtidos por Davis et al. (1997) e Berge et al. (1998) e Ahmed \& Khan (2004), com juvenis de truta arcoíris, salmão do Atlântico e carpa maior da Índia, respectivamente, que observaram redução no conteúdo de lipídios na carcaça com o aumento nos níveis de lisina nas dietas.

A adequada relação entre os aminoácidos é importante para sua utilização. Quanto à avaliação de lisina, o teor de arginina deve ser considerado, pela possibilidade de antagonismos decorrentes de dietas desbalanceadas desses aminoácidos. Neste estudo, os melhores resultados de ganho de peso e conversão alimentar foram obtidos com as relações de 0,98:1 e 0,91:1, respectivamente, de lisina:arginina.

Outro fator a ser considerado é a relação lisina:energia digestível. Neste trabalho, os melhores resultados foram obtidos com relação lisina:energia digestível de 4,45 mg de lisina digestível/kcal de energia digestível. A comparação dos dados com os trabalhos realizados anteriormente é dificultada pelo fato de que os autores não utilizaram valores de energia digestível e/ou lisina digestível.

Tabela 3 - Valores médios de água, proteína e gordura na carcaça de tilápia-do-nilo alimentadas com rações contendo níveis crescentes de lisina

Table 3 - Average values of water, protein, and fat of Nile tilapia fed diets with increasing levels of digestible lysine

\begin{tabular}{lrrrrr}
\hline \multirow{2}{*}{$\begin{array}{l}\text { Variável } \\
\text { Variable }\end{array}$} & \multicolumn{5}{c}{$\begin{array}{c}\text { Lisina digestível (\%) } \\
\text { Digestible lysine }\end{array}$} \\
\cline { 2 - 5 } & \multicolumn{1}{c}{1,04} & 1,27 & 1,51 & 1,74 & CV $^{1}$ \\
\hline Água (Water) (\%) & 76,16 & 77,51 & 75,61 & 76,30 & 0,63 \\
Proteína bruta (Crude protein) (g) & 15,46 & 15,51 & 16,32 & 16,57 & 0,82 \\
Extrato etéreo (Ether extract) (\%) & 3,89 & 3,54 & 3,87 & 3,51 & 8,78 \\
\hline
\end{tabular}

${ }^{1} \mathrm{CV}=$ coeficiente de variação (coefficient of variation).

${ }^{2}$ Efeito linear $(\mathrm{P}<0,05)$ (Linear effect): proteína bruta (crude protein) $\left(\hat{\mathrm{Y}}=12,0932+2,3338 \mathrm{X} ; \mathrm{R}^{2}=0,60\right)$. 
As diferenças nos resultados podem estar relacionadas à espécie, à composição da ração-referência, ao manejo alimentar e aos parâmetros físico-químicos da água. $\mathrm{O}$ coeficiente de digestibilidade da lisina varia entre ingredientes de acordo com sua composição em aminoácidos e com o processamento utilizado para obtenção do alimento.

Neste estudo, optou-se pelo aumento na freqüência de arraçoamento para permitir adequada utilização do aminoácido suplementado, de forma a não ocorrer um pool plasmático de lisina a uma taxa incompatível com a capacidade de utilização, permitindo adequada retenção de nitrogênio corporal e, conseqüentemente, aumento no rendimento de carcaça.

A determinação da exigência de lisina para juvenis de tilápia-do-nilo é necessária para permitir a elaboração de dietas com adequado balanceamento de aminoácidos, objetivando maximizar o crescimento, a eficiência de utilização da proteína (aminoácidos) e o rendimento de carcaça.

\section{Conclusões}

Os dados obtidos neste estudo indicam que a tilápia-donilo na fase inicial ( 5 a $30 \mathrm{~g}$ de PV) apresenta exigência de $1,44 \%$ de lisina digestível (1,55\% de lisina total), correspondente a 5,23\% da proteína digestível da dieta, para melhor desempenho, rendimento e composição química da carcaça.

\section{Literatura Citada}

AHMED, I.; KHAN, M.A. Dietary requirement of fingerling Indian major carp, Cirrhinus mrigala (Hamilton). Aquaculture, v.235, p.499-511, 2004.

BAI, S.C.; GATLIN, D.M. Effects of L-lysine supplementation of diets with different protein levels and sources on channel catfish, Ictalurus punctatus (Rafinesque). Aquaculture and Fisheries Management, v.25, p.465-474, 1994.

BERGE, G.E.; SVEIER, H.; LIED, E. Nutrition of Atlantic salmon (Salmo salar); the requirement and metabolic effect of lysine. Comparative Biochemistry and Physiology, v.120(A), p.477-485, 1998.

DAVIES, S.J.; MORRIS, P.C.; BAKER, R.T. Partial substitution of fish meal and full-fat soya bean meal with wheat gluten and influence of lysine supplementation in diets for rainbow trout, Oncorhynchus mykiss (Walbaum). Aquaculture Research, v.28, p.317-328, 1997

EUCLYDES, R.F. Manual de utilização do programa SAEG (Sistema para Análises Estatísticas e Genéticas). Viçosa, MG: Universidade Federal de Viçosa, 1983. 59p.

FAGBENRO, O.A.; BALOGUN, A.M.; FASAKIN, E.A. et al. Dietary lysine requirement of the African catfish, Clarias gariepinus. Journal of Applied Aquaculture, v.8, p.71-77, 1998.

FITZSIMMONS, K. Future trends of tilapia aquaculture in the Americas. In: COSTA PIERCE, B.A.; RAKOCY, J. (Eds.) Tilapia aquaculture in the Americas. Baton Rouge: World Aquaculture Society, 2000. p.252-264.

FORSTER, I.; OGATA, H.Y. Lysine requirement of juvenile Japanese flounder (Paralichthys olivaceus) and juvenile red sea bream (Pagrus major). Aquaculture, v.161, p.131-142, 1998.
FURUYA, W.M.; HAYASHI, C.; FURUYA, V.R.B. et al. Exigência de proteína para alevino revertido de tilápia do Nilo (Oreochromis niloticus). Revista Brasileira de Zootecnia, v.29, n.6, p.1912-1917, 2000.

FURUYA, W.M.; PEZZATO, L.E.; MIRANDA, E.C. et al Coeficientes de digestibilidade e valores de aminoácidos digestíveis de alguns ingredientes pela tilápia do Nilo (Oreochromis niloticus). Revista Brasileira de Zootecnia, v.30, n.4, 2001a.

FURUYA, W.M.; PEZZATO, L.E.; MIRANDA, E.C. et al. Coeficientes de digestibilidade aparente da energia e nutrientes de alguns ingredientes pela tilápia do Nilo, Oreochromis niloticus (L.) (linhagem tailandesa). Acta Scientiarum, v.23, n.2, p.465-469, 2001b.

FURUYA, W.M.; PEZZATO, L.E.; BARROS, M.M. et al. Use of ideal protein concept for precision formulation of amino acid levels in fish-meal-free diets for juvenile Nile tilapia (Oreochromis niloticus L.). Aquaculture Research, v.35, p.1110-1116, 2004

GRANER, C.A.F. Determinação do crômio pelo método colorimétrico da s-difenilcarbazida. Botucatu: Universidade Estadual Paulista, 1972. 112p. Tese (Doutorado em Ciências) Universidade Estadual Paulista, 1972.

JAUNCEY, K.; ROSS, B. A guide to tilapia feed and feeding. Scotland: University of Stirling, 1982. 111p.

KEEMBIYEHETTY, C.N.; GATLIN, D.M. Dietary lysine requirement of juvenile hybrid striped bass (Morone chrysops $\mathrm{x}$ M. saxatilis). Aquaculture, v.104, n.3/4, p.271-277, 1992.

KIM, K.; KAYES, T.B.; AMUNDSON, C.H. Requirements for lysine and arginine by rainbow trout (Onchorhynchus mykiss). Aquaculture, v.106, p.333-344, 1992.

MURTHY, H.S.; VARGHESE, T.J. Dietary requirement of juveniles of the indian major carp, Labeo rohita, for the essential amino acid lysine. The Israeli Journal of Aquaculture, v.49, n.1, p.19-24, 1997.

NATIONAL RESEARCH COUNCIL - NRC. Nutrient requirements of warmwater fishes and shellfishes. Washington, D.C.: National Academy Press, 1993. 102p.

NOSE, T. On the digestion of food protein by gold-fish (Carassius auratus) L.) and rainbow trout (Salmo irideus G.). Bulletin Freshwater Fisheries Research Laboratory, v.10, p.11-22, 1960.

POPMA, T.J.; GREEN, B.W. Sex reversal of tilapia in earthen ponds. Aquaculture production manual. Alabama: Auburn Unyversity, Alabama Research and Development, 1990. 15p. (Series 35).

RODEHUTSCORD, M.; BORCHERT, F.; GREGUS, Z. et al Availability and utilization of free lysine in rainbow trou (Oncorhynchus mykiss). 2. Comparison of L-lysine - $\mathrm{HCl}$ and L-lysine sulphate. Aquaculture, v.187, p.177-183, 2000.

SANTIAGO, C.B.; LOVELL, R.T. Amino acid requirements for growth of Nile tilapia. Journal of Nutrition, v.118, p.15401546, 1988.

SILVA, D.J. Análise de alimentos (Métodos químicos e biológicos) 2.ed. Viçosa, MG: Universidade Federal de Viçosa, 1990. 165p.

TIBALDI, E.; LANARI, D. Optimal dietary lysine levels for growth and protein utilisation fingerling sea bass (Dicentrarchus labrax L.) fed semipurified diets. Aquaculture, v.95, n.3/4, p.297-304, 1991

ZARATE, D.D.; LOVELL, R.T. Free lysine (L-lysine.HCl) is utilized for growth less efficiently than protein-bound lysine (soybean meal) in practical diets by young channel catfish (Ictalurus punctatus). Aquaculture, v.159, p.87-100, 1997. 